\title{
PENGARUH IMPLEMENTASI TIME AND MOTION STUDY DAN BIAYA BAHAN BAKU TERHADAP BIAYA FINISHING PRODUK PADA DEPARTEMEN FINISHING PT HARRISON \& GIL JAVA SEMARANG
}

\author{
Nadia Nurin Fajrina, Taviyastuti ${ }^{2}$, Rustono \\ Jurusan Administrasi Bisnis, Politeknik Negeri Semarang, Semarang, Indonesia \\ email: ${ }^{\text {taviyastuti@polines.ac.id }}$
}

\begin{abstract}
The aim of this research is to analyze the influence of the implementation of time and motion study and material cost on finishing cost. The amount of population is 33 wooden furniture products The analysis method of this research is path analysis with two step regression model. The result of first structural equation is Labor Cost $=0,630 \mathrm{TMS}$, and the second structural equation is Finishing Cost =0,285 Material Cost + 0,347 TMS + 0,370 Labor Cost. According to the Adjusted $R$ Square result on the first equation, time and motion study implementation contributes $37,8 \%$ on labor cost, while $62,2 \%$ is explained by other variable outside this research. Meanwhile time and motion study implementation, labor cost and material cost contribute $56 \%$ on the finishing price while $44 \%$ is explained by other variable outside this research.
\end{abstract}

Keywords: Time and Motion Study, Labor Cost, Material Cost, Production Cost

\section{PENGARUH IMPLEMENTASI TIME AND MOTION STUDY DAN BIAYA BAHAN BAKU TERHADAP BIAYA FINISHING PRODUK PADA DEPARTEMEN FINISHING PT HARRISON \& GIL JAVA SEMARANG}

\begin{abstract}
The aim of this research is to analyze the influence of the implementation of time and motion study and material cost on finishing cost. The amount of population is 33 wooden furniture products The analysis method of this research is path analysis with two step regression model. The result of first structural equation is Labor Cost $=0,630$ TMS, and the second structural equation is Finishing Cost $=0,285$ Material Cost $+0,347$ TMS $+0,370$ Labor Cost. According to the Adjusted R Square result on the first equation, time and motion study implementation contributes $37,8 \%$ on labor cost, while $62,2 \%$ is explained by other variable outside this research. Meanwhile time and motion study implementation, labor cost and material cost contribute $56 \%$ on the finishing price while $44 \%$ is explained by other variable outside this research.
\end{abstract}

Keywords: Time and Motion Study, Labor Cost, Material Cost, Production Cost

\section{PENDAHULUAN}

Sektor bisnis di berbagai negara mulai berkembang lebih pesat mengikuti perkembangan ekonomi dunia saat ini, terutama pada sektor industri manufaktur. Industri manufaktur menunjukkan perkembangan yang signifikan. Manufaktur merupakan suatu kegiatan manusia yang 
mencakup semua fase dalam kehidupan. Produk-produk manufaktur adalah semua yang ada disekitar kita, yakni: apa yang kita kenakan, kita tempati, kita lewati, bahkan sebagian besar yang kita makan semua mengalami proses manufaktur. Kata manufaktur berasal dari Bahasa Latin (manus = tangan, dan factus $=$ terbuat $)$, dan ditetapkan di kamus-kamus sebagai "membuat barang-barang dan benda- benda dengan tangan atau, khususnya dengan mesin, seringkali pada skala besar serta dengan pembagian kerja." (Schey, 2009:2).

Informasi mengenai harga material dan biaya produksi yang tepat dapat membantu perusahaan dalam menentukan harga produk yang tepat sesuai dengan kualitas produk. Selain itu, faktor produksi juga mempengaruhi harga produk. Dalam hal ini, biaya finishing dapat dipengaruhi oleh faktor- faktor produksi yaitu biaya tenaga kerja dan harga material.

PT Harrison \& Gil Java adalah perusahaan manufaktur mebel kayu yang berlokasi di Semarang, Jawa Tengah. PT Harrison \& Gil Java memproduksi mebel kayu dari produk setengah jadi menjadi produk jadi. PT Harrison \& Gil Java melakukan proses finishing produk setengah jadi melalui beberapa tahapan meliputi carving, finishing, upholstery, dan packing. Proses pengiriman produk ke luar negeri seperti Amerika, Eropa, Timur Tengah dan Tiongkok juga dilakukan oleh PT Harrison \& Gil Java.

PT Harrison \& Gil Java menerapkan metode Time and Motion Study guna membantu perusahaan dalam menentukan biaya finishing yang tepat. Hasil dari metode ini adalah waktu standar yang dihitung dengan menggunakan jam henti (stopwatch) yang kemudian dikonversikan ke dalam rupiah, di mana dalam kasus ini adalah biaya finishing yang dipengaruhi oleh biaya tenaga kerja dan biaya bahan baku. Waktu standar ini digunakan untuk menentukan upah pekerja kontrak dan pekerja borong. Berdasarkan Keputusan Gubernur Jawa Tengah Nomor 560/ 94 Tahun 2017 UMK Kota Semarang sebesar Rp 2.310.087,50, dengan masa kerja
5 hari dalam 1 minggu, 21 hari dalam 1 bulan, dan jam kerja selama 8 jam dalam satu hari. PT Harrison \& Gil Java menentukan upah pekerja kontrak dari waktu standar dikalikan dengan upah per jam, sedangkan upah pekerja borong ditentukan dari waktu standar dikali $90 \%$ dari upah per jam, dimana $10 \%$ nya menjadi keuntungan perusahaan. Semakin banyak item yang dapat diselesaikan pekerja borong, maka upah yang didapatkan akan semakin tinggi pula, oleh karena itu pekerja borong bekerja lebih cepat dari waktu standar perusahaan.

Perusahaan kembali melakukan penghitungan waktu standar dengan metode time study karena perusahaan berusaha untuk menekan biaya produksi dikarenakan adanya penurunan order sedangkan perusahaan harus mengeluarkan biaya untuk melakukan kegiatan promosi di luar negeri.

Tujuan Penelitian

Agar penelitian dapat berjalan dengan baik dan terarah, ditentukan beberapa tujuan dari penelitian ini yaitu untuk mengetahui:

1. Pengaruh implementasi Time and Motion Study terhadap biaya finishing produk mebel pada PT Harrison \& Gil Java.

2. Pengaruh biaya bahan baku terhadap biaya finishing produk mebel pada PT Harrison \& Gil Java.

3. Pengaruh implementasi Time and Motion Study dan biaya bahan baku terhadap biaya finishing produk mebel pada PT Harrison \& Gil Java.

\section{Manfaat Hasil Riset}

Penelitian ini diharapkan dapat memberikan manfaat bagi berbagai pihak yaitu:

Bagi Penulis, dapat menambah dan mengembangkan pengetahuan penulis mengenai kegiatan produksi pada departemen finishing pada PT Harrison \& Gil Java dengan implementasi Time and Motion Study dan faktor-faktor produksi yang mempengaruhi penentuan biaya finishing.

Bagi PT Harrison \& Gil Java, dapat membantu perusahaan dalam menentukan 
biaya finishing yang tepat dan seberapa besar pengaruh biaya bahan baku dan implementasi Time and Motion Study terhadap biaya finishing.

Bagi Politeknik Negeri Semarang, dapat menjadi referensi bagi mahasiswa Politeknik Negeri Semarang dalam pembuatan tugas akhir atau skripsi.

Tinjauan Pustaka

Sofjan Assauri (2016:1) menyatakan manajemen operasi produksi adalah sebuah bagian suatu organisasi yang bertanggung jawab untuk kegiatan produksi barang dan/atau jasa. Sedangkan Heizer dan Render (2009:4) berpendapat mengenai definisi manajemen operasi produksi sebagai serangkaian aktivitas yang menghasilkan nilai dalam bentuk barang dan jasa dengan mengubah input menjadi output.

Dalam proses manufaktur ada biaya yang dikeluarkan oleh perusahaan untuk kepentingan produksi. Biaya adalah "Pengorbanan sumber ekonomi, yang diukur dalam satuan uang yang telah terjadi atau kemungkinan akan terjadi untuk tujuan tertentu" (Mulyadi, 2016:8), sedangkan biaya produksi adalah "Biaya- biaya yang dikeluarkan dalam pengolahan bahan baku menjadi produk" (Muyadi, 2016:16)

Demi menekan biaya produksi, perusahaan menerapkan metode time and motion study. Time study merupakan teknik yang dirancang untuk menetapkan waktu bagi pekerja yang memenuhi syarat untuk melaksanakan pekerjaan tertentu pada tingkat kinerja yang ditentukan. (British Standard Institute dalam Kumar dan Suresh, 2008:193). Sedangkan motion study adalah "Bagian dari studi metode di mana analisis gerakan operator atau pekerjaan akan dipelajari dengan mengikuti metode yang ditentukan." (Kumar dan Suresh, 2008:190). Time study juga dapat mengurangi biaya (Meyers, 1992:4). Output dari penerapan metode ini adalah waktu standar yaitu "Waktu yang diizinkan bagi operator untuk melaksanakan tugas yang ditentukan dalam kondisi tertentu dan tingkat kinerja yang ditentukan. Waktu standar dapat didefinisikan sebagai jumlah waktu yang diperlukan untuk menyelesaikan unit kerja:

(a) dalam kondisi kerja yang ada,

(b) menggunakan metode dan mesin yang ditentukan, (c) oleh operator yang dapat bekerja dengan cara yang tepat, dan (d) dengan kecepatan standar." (Kumar dan Suresh, 2008:194). Kemudian waktu standar akan dikonversikan ke dalam rupiah sehingga perusahaan dapat menjadikan waktu standar sebagai batasan waktu penyelesaian produk dan juga sebagai patokan dalam sistem pengupahan pekerja.

\section{Hipotesis}

Hipotesis pada penelitian ini adalah:

H01:Tidak ada pengaruh antara TMS terhadap Biaya Tenaga Kerja

Ha1:Terdapat pengaruh positif antara TMS terhadap Biaya Tenaga Kerja

H02:Tidak ada pengaruh antara Biaya Tenaga Kerja terhadap Biaya Finishing

$\mathrm{Ha}$ 2:Terdapat pengaruh positif antara Biaya Tenaga Kerja terhadap Biaya Finishing

H03:Tidak ada pengaruh antara TMS terhadap Biaya Finishing

Ha3:Terdapat pengaruh positif antara TMS terhadap Biaya Finishing

H04:Tidak ada pengaruh antara Biaya Bahan Baku terhadap Biaya Finishing

$\mathrm{Ha} 4$ :Terdapat pengaruh positif antara Biaya

Bahan Baku terhadap Biaya Finishing

H05:Tidak ada pengaruh secara simultan antara Biaya Tenaga Kerja, TMS, dan Biaya Bahan Baku terhadap Biaya Finishing

Ha5:Terdapat pengaruh positif secara simultan antara Biaya Tenaga Kerja, TMS, dan Biaya Bahan Baku terhadap Biaya Finishing.

\section{METODE PENELITIAN}

Metode pengumpulan data yang digunakan dalam penyusunan penelitian ini adalah observasi, wawancara dan kajian pustaka. Seperti yang dikatakan oleh Narbuko dan Achmadi (2016:70) bahwa "Observasi atau 
pengamatan adalah alat pengumpulan data yang dilakukan dengan cara mengamati dan mencatat secara sistematik gejala-gejala yang diselidiki." Sehingga dalam penelitian ini dilakukan observasi dengan metode time and motion study pada departemen finishing untuk produk dining chair (CHR-0002) guna mengetahui waktu standar yang nantinya akan berpengaruh terhadap biaya finishing. Wawancara dilakukan dengan supervisor dari departemen Industrial Engineering untuk mendapatkan data negara ekspor, sistem pengupahan dan proses finishing produk. Sedangkan data mengenai biaya tenaga kerja, biaya bahan baku, biaya material, struktur organisasi, serta profil dan sejarah perusahaan diperoleh melalui kajian pustaka.

Data yang digunakan pada penelitian ini adalah data primer dan data sekunder. Data primer antara lain output dari metode time and motion study yang berupa waktu standar. Data sekunder diperoleh dari departemen Industrial Engineering PT Harrison \& Gil Java Semarang yang berupa data biaya tenaga kerja, biaya bahan baku, dan biaya finishing. Data penelitian ini berupa data cross-section dari bulan Januari hingga Maret 2018 dengan populasi berjumlah 33 produk dining chair (CHR-0002).

Dalam analisis data dengan menggunakan regresi terdapat beberapa asumsi yang harus dipenuhi sehingga persamaan regresi yang dihasilkan memenuhi kriteria best fit model. Model regresi dapat disebut sebagai model yang baik apabila memenuhi kriteria BLUE (Best Linear Unbiased Estimator). Kriteria BLUE dapat dicapai bila memenuhi syarat uji asumsi klasik yaitu Uji Normalitas, Uji Heteroskedastisitas, Uji Linearitas, Uji Autokorelasi, dan Uji Multikolinearitas (Lupiyoadi dan Ikhsan, 2016:134).

Untuk menguji hipotesis dalam penelitian ini dilakukan regresi dua tahap, yaitu regresi linear sederhana dan regresi linear berganda. Variabel bebas dalam penelitian ini adalah time and motion study (X1) dan Biaya Bahan Baku (X2), variabel intervening dalam penelitian ini adalah Biaya Tenaga Kerja (Y) dan variabel terikat dalam penelitian ini adalah Biaya Finishing (Z). Model dari regresi dua tahap (sederhana dan berganda) secara umum adalah sebagai berikut:

$\mathrm{Y}=\beta 1 \mathrm{X} 1+e$

$\mathrm{Z}=\beta 1 \mathrm{X} 1+\beta 2 \mathrm{X} 2+\beta 3 \mathrm{Y}+e$

Keterangan:

$\beta=$ nilai koefisien regresi

$\mathrm{X} 1=$ time and motion study

$\mathrm{X}_{2}=$ Biaya bahan baku

$\mathrm{Y}=$ Biaya tenaga kerja

$\mathrm{Z}=$ Biaya finishing

$e=$ error

Setelah dilakukan analisis regresi duatahap, perlu dilakukan uji kelayakan model (goodness of fit test) untuk mengetahui sejauh mana model regresi dapat menjelaskan hubungan antara variabel bebas dan terikat. Uji kelayakan model pada penelitian ini meliputi uji hipotesis baik secara parsial dengan Uji t dan secara simultan dengan Uji F serta Uji Koefisien Determinasi Disesuaikan (Adjusted R Square).

Kemudian untuk menguji pengaruh mediasi yang ada antara variabel TMS dan Biaya Finishing, digunakan analisis jalur sehingga dapat diketahui pengaruh langsung, pengaruh tidak langsung dan penaruh total antar variabel. Penentuan signifikansi pengaruh tidak langsung dilakukan dengan menggunakan Uji Sobel.

\section{HASIL DAN PEMBAHASAN}

Berdasarkan hasil uji asumsi klasik pada kedua model regresi, diketahui bahwa nilai Asymp. Sig. lebih besar dari taraf signifikansi, dan berdasarkan P-Plot Chart titik-titik menyebar disekitar garis diagonal sehingga dapat disimpulkan bahwa data berdistribusi normal.

Uji Heterskedastisitas dilakukan dengan menggunakan scatter plot diagram dan Uji Glejser. Dari kedua model regresi, titik-titik pada scatter plot diagram menyebar di atas maupun di bawah 0 dan sumbu Y, dan hasil 
Uji Glejser menunjukkan nilai signifikansi lebih besar dari taraf signifikansi sehingga dapat disimpulan kedua model regresi tersebut bebas dari indikasi heteroskedastisitas.

Uji linearitas dilakukan dengan menggunakan Lagrange Multiplier test dan hasil dari kedua model regresi adalah nilai c2 hitung lebih kecil dari nilai c2 tabel yang artinya bahwa hubungan antar variabel adalah linear.

Begitu juga dengan Uji Multikolinearitas pada model persamaan regresi ke dua di mana nilai Tolerance masing-masing variabel lebih besar dari 0,1 dan nilai VIF kurang dari 10 , yang artinya bahwa tidak ada hubungan antar variabel bebas pada penelitian ini.

\section{Hasil Regresi}

Dengan menggunakan SPSS, diperoleh hasil persamaan regresi sebagai berikut:

$\mathrm{BTK}=0,630 \mathrm{TMS}$

$\mathrm{BF}=0,285 \mathrm{BBB}+0,347 \mathrm{TMS}+0,370$ BTK

Keterangan:

BF : Biaya Finishing (Z)

BBB : Biaya Bahan Baku (X2)

TMS : Time and Motion Study (X1)

BTK : Biaya Tenaga Kerja (Y)

Nilai koefisien regresi TMS pada model persamaan pertama adalah 0,630 menunjukkan bahwa setiap peningkatan 1 jam TMS maka akan meningkatkan biaya tenaga kerja sebanyak 0,630 rupiah dengan asumsi variabel lain tetap (ceteris paribus).

Pada persamaan kedua, nilai koefisien regresi biaya bahan baku adalah 0,285 menunjukkan bahwa setiap peningkatan 1 rupiah biaya bahan baku maka akan meningkatkan biaya finishing sebesar 0,285 rupiah dengan asumsi variabel lain tetap (ceteris paribus).

Nilai koefisien regresi TMS adalah 0,347 menunjukkan bahwa setiap peningkatan 1 jam TMS makaakan meningkatkan biaya finishing sebesar 0,347 rupiah dengan asumsi variabel lain tetap (ceteris paribus).
Nilai koefisien regresi biaya tenaga kerja adalah 0,370 menunjukkan bahwa setiap peningkatan 1 rupiah biaya tenaga kerja maka akan meningkatkan biaya finishing sebesar 0,370 rupiah dengan asumsi variabel lain tetap (ceteris paribus).

\section{Hasil Pengujian Hipotesis}

Hasil Uji t (parsial) pada persamaan pertama adalah nilai $t$ hitung variabel TMS sebesar 4,522 lebih besar dari nilai $\mathrm{t}$ tabel yaitu sebesar 1,699 dan nilai signifikansi adalah 0,000 lebih kecil dari taraf signifikansi 0,05, sehingga berdasarkan hasil tersebut Ho1 ditolak dan Ha1 diterima dengan kata lain terdapat pengaruh positif dan signifikan antara variabel TMS terhadap variabel biaya tenaga kerja.

Hasil Uji t (parsial) pada persamaan kedua adalah nilai $\mathrm{t}$ hitung variabel biaya bahan baku sebesar 2,260 lebih besar dari nilai $t$ tabel yaitu sebesar 1,699 dan nilai signifikansi adalah 0,032 lebih kecil dari taraf signifikansi 0,05, sehingga berdasarkan hasil tersebut $\mathrm{Ho} 2$ ditolak dan $\mathrm{Ha} 2$ diterima dengan kata lain terdapat pengaruh positif dan signifikan antara variabel biaya bahan baku terhadap variabel biaya finishing. Nilai $\mathrm{t}$ hitung variabel TMS sebesar 2,160 lebih besar dari nilai $\mathrm{t}$ tabel yaitu sebesar 1,699 dan nilai signifikansi adalah 0,039 lebih kecil dari taraf signifikansi 0,05 , sehingga berdasarkan hasil tersebut Ho3 ditolak dan Ha3 diterima dengan kata lain terdapat pengaruh positif dan signifikan antara variabel TMS terhadap variabel biaya finishing. Nilai thitung variabel biaya tenaga kerja sebesar 2,434 lebih besar dari nilai t tabel yaitu sebesar 1,699 dan nilai signifikansi adalah 0,021 lebih kecil dari taraf signifikansi $0,05, \quad$ sehingga berdasarkan hasil tersebut $\mathrm{Ho} 4$ ditolak dan Ha4 diterima dengan kata lain terdapat pengaruh positif dan signifikan antara variabel biaya tenaga kerja terhadap variabel biaya finishing.

Berdasarkan hasil uji simultan (F) diketahui nilai signifikansi adalah 0,000 lebih kecil dari 
taraf signifikansi 0,005 serta nilai $\mathrm{F}$ hitung adalah sebesar 14,555 lebih besar dari nilai $\mathrm{F}$ tabel yaitu 2,80 sehingga Ho5 ditolak dan Ha5 diterima yang artinya variabel biaya bahan baku, TMS dan biaya tenaga kerja secara simultan atau bersama sama berpengaruh terhadap biaya finishing.

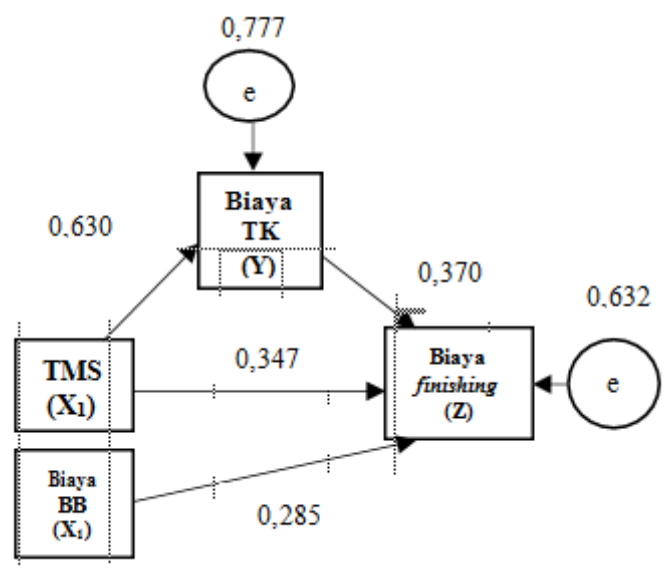

Gambar 1 Diagram Jalur

\section{Hasil Koefisien Determinasi Disesuaikan (Adjusted R Square)}

Hasil regresi pada persamaan pertama menunjukkan nilai Adjusted $R$ Square adalah sebesar 0,378 artinya variabel Time and Motion Study memiliki pengaruh sebesar $37,8 \%$ terhadap variabel biaya tenaga kerja. Sedangkan sisanya $62,2 \%$ dijelaskan oleh faktor lain diluar penelitian. Sedangkan pada hasil regresi persamaan kedua nilai Adjusted $R$ Square adalah sebesar 0,560, artinya variabel biaya bahan baku, biaya tenaga kerja dan time and motion study memiliki pengaruh sebesar $56 \%$ terhadap variabel biaya Finishing. Sedangkan sisanya 44\% dijelaskan oleh faktor lain di luar penelitian.

\section{Hasil Analisis Jalur}

Pengaruh langsung antara variabel TMS (X1) terhadap variabel biaya finishing (X2) adalah 0,630. Sedangkan pengaruh tidak langsung merupakan pengaruh antara variabel TMS (X1) terhadap variabel biaya finishing (Z) melalui variabel biaya tenaga kerja (Y). Hasil pengaruh tidak langsung merupakan perkalian antara nilai koefisien standar TMS (X1) terhadap biaya tenaga kerja (Y) dan nilai koefisien standar TMS (X1) terhadap biaya finishing $(\mathrm{Z})$ yaitu $0,630 \times 0,370=0,233$

\section{Hasil Uji Sobel}

Uji Sobel digunakan untuk menguji signifikansi dari nilai pengaruh mediasi atau pengaruh tidak langsung antara variabel TMS terhadap variabel biaya finishing melalui variabel biaya tenaga kerja.

$$
\begin{aligned}
\mathrm{Sp} 2 \mathrm{p} 3 & =\sqrt{p 3^{2} S p 2^{2}+p 2^{2} S p 3^{2}+S p 2^{2} S p 3^{2}} \\
& =\sqrt{\begin{array}{r}
(0,580)^{2}(6836,989)^{2}+(30917,205)^{2}(0,283)^{2} \\
+(6836,989)^{2}(0,283)^{2^{2}}
\end{array}} \\
& =\sqrt{(15724822,417)+(76469885,201)+(3739553,48 \dot{9})} \\
& =9794,604
\end{aligned}
$$

Berdasarkan hasil Sp2p3, dapat dihitung nilai $\mathrm{t}$ statistik pengaruh mediasi. Nilai $\mathrm{t}$ hitung adalah 1,831 lebih besar dari nilai t tabel yaitu 1, sehingga dapat disimpulkan bahwa koefisien mediasi 0,233 signifikan, yang artinya ada pengaruh tidak langsung antara variabel TMS dengan variabel biaya finishing.

\section{Pembahasan}

Analisis regresi linear sederhana pada penelitian ini adalah untuk menguji pengaruh implementasi Time and Motion Study (X1) 
terhadap biaya tenaga kerja (Y) pada PT Harrison \& Gil Java Semarang. Dengan melihat nilai koefisien regresi, variabel TMS memiliki pengaruh positif terhadap biaya tenaga kerja dengan koefisien regresi yaitu 0,630 yang artinya jika ada kenaikan output implemetasi time and motion study (standard time) selama 1 jam, maka akan meningkatkan biaya tenaga kerja sebanyak 0,630 rupiah. Berdasarkan hasil uji signifikansi parsial (Uji t) nilai t hitung variabel TMS adalah 4,522 lebih besar dari nilai $\mathrm{t}$ tabel yaitu 1,696 dengan nilai signifikan 0,000 artinya variabel TMS (X1) berpengaruh positif dan signifikan terhadap variabel biaya tenaga kerja (X2). Sedangkan berdasarkan uji sobel nilai t hitung adalah 1,831 lebih besar dari nilai t tabel yaitu 1,699 sehingga dapat disimpulkan terdapat pengaruh tidak langsung atau pengaruh mediasi antara variabel TMS (X1) terhadap biaya finishing (Z) melalui variabel biaya tenaga kerja (Y).

Analisis regresi linear berganda pada penelitian ini adalah untuk menguji pengaruh implementasi Time and Motion Study (X1), biaya bahan baku (X2) dan biaya tenaga kerja (Y) terhadap biaya finishing (Z) pada PT Harrison \& Gil Java Semarang Dengan melihat nilai koefisien regresi, variabel biaya tenaga kerja memiliki pengaruh positif terhadap biaya finishing dengan nilai koefisien regresi yaitu 0,370 yang artinya jika ada kenaikan biaya tenaga kerja sebesar 1 rupiah, maka akan meningkatkan biaya finishing 0,370 rupiah. Berdasarkan hasil uji signifikansi parsial (Uji t) nilai t hitung variabel biaya tenaga kerja adalah 2,434 lebih besar dari nilai t tabel yaitu 1,699 dan dengan nilai signifikan 0,021 artinya variabel biaya tenaga kerja (Y) berpengaruh positif dan signifikan terhadap variabel biaya finishing (Z).

Nilai koefisien regresi, variabel time and motion study memiliki pengaruh positif terhadap biaya finishing dengan nilai koefisien regresi yaitu 0,347 yang artinya jika ada kenaikan output implementasi time and motion study (waktu standar) selama 1 jam, maka akan meningkaan biaya finishing sebesar 0,347 rupiah. Berdasarkan hasil uji signifikansi parsial (Uji t) nilai $\mathrm{t}$ hitung variabel time and motion study adalah 2,160 lebih besar dari nilai t tabel yaitu 1,699 dan dengan nilai signifikan 0,039 artinya variabel time and motion study (X1) berpengaruh positif dan signifikan terhadap variabel biaya finishing $(\mathrm{Z})$.

Nilai koefisien regresi, variabel biaya bahan baku memiliki pengaruh positif terhadap biaya finishing dengan nilai koefisien regresi yaitu 0,285 yang artinya jika ada kenaikan biaya bahan baku sebesar 1 rupiah, maka akan meningkaan biaya finishing sebesar 0,285 rupiah. Berdasarkan hasil uji signifikansi parsial (Uji t) nilai $t$ hitung variabel biaya bahan baku adalah 2,260 lebih besar dari nilai t tabel yaitu 1,699 dan dengan nilai signifikan 0,032 artinya variabel biaya bahan baku (X2) berpengaruh positif dan signifikan terhadap variabel biaya finishing (Z).

\section{SIMPULAN DAN SARAN}

Berdasarkan hasil dari penelitian mengenai pengaruh implementasi Time and Motion Study dan biaya bahan baku terhadap biaya finishing produk mebel pada PT harrison \& Gil Java terdapat beberapa faktor yang dapat mempengaruhi biaya finishing antara lain yaitu implementasi time and motion study, biaya tenaga kerja dan biaya bahan baku. Dalam penelitian ini terdapat pengaruh tidak langsung antara variabel time and motion study dan variabel biaya finishing. Variabel biaya tenaga kerja menjadi variabel intervening atau mediator yang menghubungkan variabel time and motion study dan biaya finishing. Variabel time and motion study berpengaruh positif dan signifikan terhadap variabel biaya tenaga kerja sebesar 0,630. Variabel biaya tenaga kerja berpengaruh positif dan signifikan terhadap variabel biaya finishing sebesar 0,370. Begitu juga dengan variabel time and motion study berpengaruh positif dan 
signifikan terhadap variabel biaya finishing sebesar 0,347 serta variabel biaya bahan baku berpengaruh positif dan signifikan terhadap variabel biaya finishing sebesar 0,289. Dan secarasimultan variabel time and motion study, biaya tenaga kerja dan biaya bahan baku berpengaruh positif dan signifikan terhadap variabel biaya finishing dengan nilai Adjusted $R$ square sebesar 0,560 atau ketiga variabel tersebut memiliki kontribusi terhadap biaya finishing sebesar 56\%.

Hasil tersebut menunjukkan bahwa variabel biaya tenaga kerja adalah yang paling dominan dengan nilai koefisien regresi 0,370 sehingga jika perusahaan ingin menekan biaya produksi, maka perusahaan perlu memperhatikan faktor biaya tenaga kerja. Melalui penerapan metode time and motion study, perusahaan dapat menentukan waktu standar pengerjaan produk sehingga biaya tenaga kerja dapat dikendalikan dengan menggunakan metode tersebut.

PT Harrison \& Gil Java perlu menerapkan metode Time and Motion Study pada departemen lain seperti departemen Upholstery dan Packing, guna menentukan waktu standar pekerjaan sehingga dapat meningkatkan produktivitas dan menekan biaya tenaga kerja bagi pekerja borong. Pelaksanaan metode Time and Motion Study perlu dilakukan berulang secara rutin mengingat kinerja tiap pekerja yang dapat semakin lama semakin meningkat atau bahkan menurun karena adanya pekerja baru yang belum berpengalaman yang nantinya dapat mempengaruhi produktivitas dan biaya tenaga kerja.

\section{DAFTAR PUSTAKA}

Ghozali, Imam. 2018. Aplikasi Analisis Multivariate Dengan Program IBM SPSS 25 Edisi 9. Universitas Diponegoro

Heizer, Jay dan Render. 2009. Manajemen Operasi Edisi 9 Buku 1. Jakarta: Salemba Empat

Kumar, S. Anil \& N. Suresh. 2008. Production and Operations Management (With Skill Development, Caselets and Cases) 2nd Edition. New Delhi: New Age International Publisher.

Lupiyoadi, Rambat dan Ridho Bramulya. Ikhsan. 2015. Praktikum Metode Riset Bisnis. Jakarta: Salemba Empat.

Meyers, Fred E.. 1992. Motion And Time Study Improving Work Methods and Management. New Jersey: Prentice-Hall.

Mulyadi. 2016. Akuntansi Biaya. Yogyakarta: STIM YKPN.

Narbuko, Cholid dan H.Abu Achmadi. 2016. Metodologi Penelitian. Bumi Aksara

Prof. Dr. Assauri, Sofjan. 2016. Manajemen Operasi Produksi Pencapaian Sasaran Organisasi

Berkesinambungan. Jakarta: PT Rajagrafindo Persada.

Schey, John A. 2009. Proses Manufaktur. Yogyakarta: ANDI 